\title{
Energy Savings from Temperature Setpoints and Deadband: Quantifying the Influence of Building and System Properties on Savings
}

\author{
Ali Ghahramani ${ }^{\text {a }}$, Kenan Zhang ${ }^{\mathrm{b}}$, Kanu Dutta ${ }^{\mathrm{c}}$, Zheng Yang ${ }^{\mathrm{d}}$, Burcin Becerik-Gerber ${ }^{\mathrm{e}}$ \\ ${ }^{a}$ PhD Student, Sonny Astani Dept. of Civil and Environmental Engineering, Viterbi School of \\ Engineering, Univ. of Southern California, KAP 217, 3620 South Vermont Ave., Los Angeles, CA \\ 90089-2531. E-mail: aghahram@usc.edu \\ ${ }^{\mathrm{b}}$ Graduate Student, Sonny Astani Dept. of Civil and Environmental Engineering, Viterbi School of \\ Engineering, Univ. of Southern California, KAP 217, 3620 South Vermont Ave., Los Angeles, CA \\ 90089-2531.E-mail: kenanz@andrew.cmu.edu \\ ${ }^{\mathrm{c}}$ Graduate Student, Sonny Astani Dept. of Civil and Environmental Engineering, Viterbi School of \\ Engineering, Univ. of Southern California, KAP 217, 3620 South Vermont Ave., Los Angeles, CA \\ 90089-2531.E-mail: kdutta@usc.edu \\ ${ }^{\mathrm{d}} \mathrm{PhD}$ Candidate, Sonny Astani Dept. of Civil and Environmental Engineering, Viterbi School of \\ Engineering, Univ. of Southern California, KAP 217, 3620 South Vermont Ave., Los Angeles, CA \\ 90089-2531. E-mail: zhengyan@usc.edu \\ ${ }^{\mathrm{e}}$ Associate Professor, Sonny Astani Dept. of Civil and Environmental Engineering, Viterbi School of \\ Engineering, Univ. of Southern California, KAP 224C, 3620 South Vermont Ave., Los Angeles, CA \\ 90089-2531. E-mail: becerik@usc.edu, Tel: +1 2137404383 (Corresponding Author)
}

\begin{abstract}
This paper provides a systematic approach for quantifying the influence of building size, construction category, climate, occupancy schedule, setpoint, and deadband on HVAC energy consumption in office buildings. Simulating the DOE reference office buildings of three sizes and three construction categories in all United States climate zones, using the EnergyPlus, we conducted several N-way ANOVA analyses to study the interrelationships between setpoints, deadbands and several building related and environment related factors. In summary, daily optimal deadband selection of $0,1,2,4,5$, and $6 \mathrm{~K}$ would result in an average energy savings of $-70.0,-34.9,-13.7,9.6,16.4$, and $21.2 \%$, respectively, compared to baseline deadline of $3 \mathrm{~K}$. Selecting the daily optimal setpoint in the range of $22.5 \pm 1{ }^{\circ} \mathrm{C}, 22.5 \pm 2{ }^{\circ} \mathrm{C}$, and $22.5 \pm 3$ ${ }^{\circ} \mathrm{C}$ would result in an average savings of $7.5,12.7$, and $16.4 \%$, respectively, compared to the baseline setpoint of $22.5^{\circ} \mathrm{C}$. Additionally, we found that when the outdoor temperature is within -20 to $30^{\circ} \mathrm{C}$, the optimal setpoint depends on the building size. We also observed a range of outdoor temperatures (e.g., 9 $14{ }^{\circ} \mathrm{C}$ for small buildings and $8-11^{\circ} \mathrm{C}$ for medium buildings) where the setpoint selection would only slightly influence the energy consumption. However, the choice of setpoints becomes very influential (up to $30 \%$ of energy savings) where the outdoor temperatures are slightly outside the mentioned ranges on either direction. The potential savings from selecting daily optimal setpoints in the range of $22.5 \pm 3{ }^{\circ} \mathrm{C}$ in different climates and for small, medium and large office buildings, would lead to $10.09-37.03 \%$, $11.43-21.01 \%$, and $6.78-11.34 \%$ savings, respectively, depending on the climate.
\end{abstract}

\section{KEYWORDS:}

HVAC system; energy consumption; setpoint; deadband; control parameters; building characteristics; climate; savings

\section{INTRODUCTION}

Commercial buildings account for about $18.9 \%$ of the energy consumption and $19.6 \%$ of the total greenhouse gas emissions in the United States [1,2]. There are several techniques that can help building stakeholders to reduce energy consumption in buildings and consequently reduce the associated greenhouse gas emissions. Among some of these techniques are advanced system operations and 
maintenance[3], standard and deep retrofits, and techniques that would control and manage the demand, including smart grid applications [3-5]. However, these approaches focus on the physical systems with fixed requirements. Building systems are operated to meet occupants needs which could be unique and may change over time. Learning the dynamic needs of occupants, in terms of services from building systems, can potentially lead to improved energy efficiency. Only a few research efforts has focused on the quantification of potential energy savings from integration of occupant needs into the control logic of building systems [6,7]. In this paper, we specifically focus on quantifying potential energy savings in Heating, Ventilation, and Air Conditioning (HVAC) systems through set point (i.e., the target temperature that HVAC system tries to maintain) and deadband (i.e., the range around the setpoint at which the system is not required to respond) adjustments as these systems account for the largest share of the energy usage and gas emissions (43\% of the commercial building energy consumption) [1].

HVAC systems in buildings are primarily responsible for providing satisfactory thermal conditions and indoor air quality for building occupants. The common practice of defining operational settings for HVAC systems is to use fixed setpoints, which assume occupants have static comfort requirements. However, it is proven that humans perceive comfort in a range of environmental thermal conditions [8]. In addition, many dynamic environment related variables (e.g., weather [8]) and human related variables (e.g., acclimation [9]) effect thermal comfort and therefore, the individuals' thermal comfort ranges change over time [10-13]. Given the range of comfortable conditions for an occupant, we can potentially control a service system to provide thermal conditions in that range while minimizing the overall energy consumption [6,7]. However, there are several other factors, such as building type and size, insulation and construction materials, HVAC system operation efficiency, climate, and occupant behavior, which also influence overall building energy consumption. The amount of energy savings related to comfort-aware HVAC setpoints with respect to different factors could be used as heuristics for building stakeholders to decide on the strategy for comfort-aware and energy-efficient HVAC operations.

In this paper, we introduce a systematic approach for quantifying the effects of a number of factors on overall building energy consumption. We specifically focus on the HVAC control parameters (i.e., set points and deadband) and study how occupancy, building, and outdoor environment influence savings from optimal selection of these control parameters. We explore the optimal annual setpoints in each climate, along with quantification of their potential energy savings. In addition to the annual setpoints, we study daily optimal setpoints, as well as their relationship with outdoor temperature in different climates. In comparison with the optimal setpoints, optimal deadbands and their relationships to other factors are also studied in this paper. For our investigations, we used Department of Energy (DOE) reference commercial building models [14], which are EnergyPlus software simulation files. These models represent $70 \%$ of the commercial buildings stock in the United States. In this study, we focus on office buildings and use small, medium, and large size office buildings in three different construction categories

(e.g., built after 2004, built after 1980 - before 2004, and built before 1980) in all climate zones of the United States.

The paper is structured as follows. Section 2 provides a review of recent studies on the influence of temperature setpoints on building energy consumption. In Section 3, we introduce a systematic approach for identifying the influential factors on setpoint-energy consumption and we quantify the savings from annual and daily setpoint selection strategies. In section 4, the DOE energy simulation models and simulation procedures are discussed. We present the results of our methodology in section 5. Section 6 provides a discussion on the generalization of the results and limitations and future steps of the study. Finally, section 7 summarizes the results and concludes the paper.

\section{LITERATURE REVIEW}

HVAC system controllers often work with a negative feedback single temperature control loop [15,16]. A controller adjusts several internal variables to provide air with different flow rates, temperatures and humidity to keep the difference between thermostat readings and a setpoint in a certain range. The range around the setpoint at which no action is required from a system is called the deadband. HVAC systems, 
similar to any other mechanical system, require to have a non-negative deadband (any value greater or equal to 0) around the target setpoint to maintain stability. When the thermostat reading lies within the deadband range, the system only provides minimum airflow to maintain acceptable air quality (ASHRAE Standard 62.1 (Ventilation for Acceptable Indoor Air Quality) [17]). The temperature at which the system begins heating is called the heating setpoint (associated with the higher value on the deadband) and the temperature at which cooling starts is called the cooling setpoint (associated with the lower value on the deadband). Previous research efforts have tried to quantify the influence of setpoints by extending the deadband [18,19]. HVAC systems operate based on a single input/single output control logic (i.e., univariate control as opposed to bivariate control of both heating and cooling setpoints) [16]. Therefore, adjusting solely the setpoint fits to this operation logic.

A study on the influence of widening the deadband on energy consumption of medium-sized office DOE reference buildings built between 1980 and 2004 and built after 2004 was conducted by the authors in [19]. They carried out the study for 7 different cities (climate zones): Miami, Phoenix, Fresno, San Francisco, Baltimore, Chicago, and Duluth. The baseline setpoint range was $21.1{ }^{\circ} \mathrm{C}$ (heating setpoint) and $22.2{ }^{\circ} \mathrm{C}$ (cooling setpoint). The heating setpoint was extended to $17.7^{\circ} \mathrm{C}$ and the cooling setpoint was extended to $30{ }^{\circ} \mathrm{C}$. The results showed that through increasing the cooling setpoint of $22.2{ }^{\circ} \mathrm{C}$ to $25^{\circ} \mathrm{C}$, an average of $29 \%$ of the cooling energy and $27 \%$ of the total HVAC energy savings could be achieved. Their findings also pointed that an $18.3-27.8{ }^{\circ} \mathrm{C}$ temperature range could save $32 \%$ to $73 \%$ of the total HVAC energy consumption, depending on the climate. The authors also argued that the savings can be achieved through occupant involvement in control of HVAC systems [19]. The same authors in their previous studies [18] found that extending the setpoint range from $21.1-23.9{ }^{\circ} \mathrm{C}$ to $20.6-25{ }^{\circ} \mathrm{C}$ reduces between 13 to $28 \%$ HVAC energy consumption on different types of medium-sized office buildings. In another study on the large office DOE reference buildings [20], the authors showed that extending the temperature setpoints range from 21.6 to $22.8{ }^{\circ} \mathrm{C}$ to 20.6 to $23.9^{\circ} \mathrm{C}$ reduced the energy consumption by 9 to $20 \%$ depending on the climate and time of the year. However, the influence of heating and cooling setpoints extension on actual setpoints and deadband remains unclear. In addition extending the difference between cooling and heating setpoints would always lead to energy savings. Accordingly, it is unaddressed which cooling and heating setpoints are optimal for a certain climate. Furthermore, the impact of outdoor weather on energy consumption at different setpoints were not explored in these studies.

The authors in [21] evaluated the effects of temperature setpoints and deadband on the HVAC system energy consumption and occupant thermal comfort in two cities (i.e., Copenhagen and Madrid). The setpoints ranged from $19{ }^{\circ} \mathrm{C}$ to $33{ }^{\circ} \mathrm{C}$ and the deadbands were $\pm 1 \mathrm{~K}$ and $\pm 2 \mathrm{~K}$ at $21{ }^{\circ} \mathrm{C}$. The case study building was a one story, single family house with an area of $66.2 \mathrm{~m}^{2}$ and a conditioned volume of 213 $\mathrm{m}^{3}$. The results showed that the deadband had a significant influence on the thermal comfort as it required the occupants to adapt to a wider range of thermal environment. They also found that temperature setpoints had higher impacts on the energy consumption and the occupant thermal comfort. Potential 23\% and 34\% energy savings were realized during the heating season in Copenhagen and Madrid, respectively. In the cooling season, the potential savings were $17 \%$ and $10 \%$ in Copenhagen and Madrid, respectively. The authors concluded that understanding occupants' actual comfort requirements is the key to use this potential savings from temperature setpoints. In this study, the range of deadbands were only studied at a fixed setpoint and the interdependencies between deadbands and setpoints were not studied. In addition, the impact of system dynamics like weather conditions and other influential factors were not part of the investigation

Not only HVAC control parameters impact a building's energy consumption, but they also play an important role in occupants' thermal comfort. Authors in [22] studied the influence of cooling setpoints in air-conditioned offices on occupants' thermal perception and satisfaction in the United Kingdom via surveys. Their results demonstrated that even though higher cooling set points increased the perception of warmer conditions, the occupants' thermal comfort levels were not affected significantly, which suggested that potential energy savings in warmer seasons could be achieved if higher cooling set points 
were used. However, HVAC control parameters' influence on energy consumption also depends on the operational conditions. Heat transfer between a building and its environment works based on the heat gradient between the indoor environment and outdoor environment. Hence, climate also influences the amount of energy consumption. Building size also play an important role in heat transfer between inside and outside of a building as the internal parts of the buildings are often less influenced by the outdoor conditions due to insulations at the perimeters. Consequently, an energy saving technique, which performs well in a certain climate and for a certain building size might not perform as well in another climate [23]. In order to approach optimality in HVAC energy efficiency, building characteristics and specifications also need to be studied and evaluated [24-26].

In summary, previous efforts have not statistically analyzed the savings from adjusting setpoints with respect to other factors, such as the climate, construction category, and the deadband. Although it is common to use the same heating and cooling setpoints throughout the year, daily setpoints could also be practical while their contributions to energy efficiency have not yet been quantified. In addition, there needs to be a systematic approach to help building stakeholders to compare the influence of different factors on building energy consumption and also to understand the dynamic (time dependent) impacts of control parameters on the energy consumption.

\section{METHODOLOGY}

To address these gaps in research, we followed a systematic approach for quantifying the influence of factors that contribute to the HVAC energy consumption. We selected two control parameters (i.e., temperature setpoints, and the deadband), three occupancy schedules (i.e., weekdays, Saturdays, and Sundays/holidays), all U.S. climates (i.e., 16 climates described in Section 4), three building sizes (i.e., small, medium, and large), and three construction categories (i.e., new construction (after 2004) existing buildings (after 1980 - before 2004), existing buildings (before 1980)). The detailed explanation of the climates and construction categories can be found in Section 4. Through defining the contributing factors, we identified the discrete (categorical) and continuous factors. In this case, four factors (i.e., climate, construction category, building size and occupancy schedules) were discrete (categorical), and two factors (i.e., temperature setpoints and deadband) were continuous. However, in order to compare the significance of the factors on energy consumption, we also had to discretize the continuous factors. Although there are various mathematical techniques for discretization, the granularity of the discretized factors is highly dependent on the building stakeholder requirements. On the other hand, a more detailed analysis increases the computational cost by the order of parameters' space size. In this paper, we studied the setpoints and the deadbands by assigning the granularity of $1{ }^{\circ} \mathrm{C}$ (i.e., $1 \mathrm{~K}$ ). We also defined the range, in which the continuous parameters are likely to be chosen. This range also depends on the occupant thermal comfort requirements. In this study, we decided the minimum and maximum temperature setpoints to be 19.5 and $26.5^{\circ} \mathrm{C}$, respectively. Considering a deadband of $6 \mathrm{~K}$, the resulting cooling and heating setpoints cover a wide range of setpoints $\left(16.5^{\circ} \mathrm{C}\right.$ to $29.5{ }^{\circ} \mathrm{C}$, respectively). These setpoints are greater than the values used in different studies [18-21]. For the deadband, we selected $0,1,2 \mathrm{~K}, 3 \mathrm{~K}$ (pre-set deadband on the DOE reference buildings), $4 \mathrm{~K}, 5 \mathrm{~K}$, and $6 \mathrm{~K}$. Again, various values of deadband can be studied based on stakeholders' preferences, however values greater than $6 \mathrm{~K}$ would require occupants to pursue individual adaptation procedures to achieve comfort. Table 1 summarizes all the conditions, in which the simulations were carried out. There were 7056 distinct cases for each permutation.

Table 1. Factor categories used in the n-way ANOVA analysis

\begin{tabular}{ccccc}
\hline Setpoint & Deadband & City (Climate) & Construction Category & Size \\
\hline $19.5{ }^{\circ} \mathrm{C}$ & $6 \mathrm{~K}$ & Miami, Florida (1A) & New construction (after 2004) & Small \\
$20.5{ }^{\circ} \mathrm{C}$ & $5 \mathrm{~K}$ & Houston, Texas (2A) & Existing buildings (after 1980 - before & Medium \\
$21.5{ }^{\circ} \mathrm{C}$ & $4 \mathrm{~K}$ & Phoenix, Arizona (2B) & Existing buildings (before 1980) & Large
\end{tabular}




$\begin{array}{ccc}22.5^{\circ} \mathrm{C} & 3 \mathrm{~K} & \text { Atlanta, Georgia (3A) } \\ 23.5^{\circ} \mathrm{C} & 2 \mathrm{~K} & \text { Los Angeles, California (3B) } \\ 24.5^{\circ} \mathrm{C} & 1 \mathrm{k} & \text { Las Vegas, Nevada (3B) } \\ 25.5^{\circ} \mathrm{C} & & \text { San Francisco, California } \\ & & \text { (3C) } \\ & \text { Baltimore, Maryland (4A) } \\ & \text { Albuquerque, New Mexico } \\ & \text { (4B) } \\ & \text { Seattle, Washington (4C) } \\ & \text { Chicago, Illinois (5A) } \\ & \text { Denver, Colorado (5B) } \\ & \text { Minneapolis, Minnesota } \\ & \text { (6A) } \\ & \text { Helena, Montana (6B) } \\ & \text { Duluth, Minnesota (7) } \\ & \text { Fairbanks, Alaska (8) }\end{array}$

Through discretizing the continuous variables, we developed a set of feasible conditions that simulation models can provide insights into the factors' influence. The next step is to define the simulation period. Simulation models can be run on daily, monthly, seasonal, and yearly bases. The choice of the simulation period also depends on the stakeholder preferences. In this study, we set the duration to be a year. We chose a year period because it covers climatic variations. Therefore, the results are not biased to a specific season (e.g., hot season or cold season). We then run the simulation models via a programming language (i.e., MATLAB software) for all permutations of factors. To do so, prior to the simulation for each permutation, we modified the building energy model file (i.e., .idf file). We searched the model's text file to locate the factor and replace the desired values. The output of the simulation provides energy usage and other internal variables for one year on an hourly basis. For comparing the results of each permutation, we took the summation of all energy usage data and represent it as one value. In the summation process, we also considered the effects of simulation warm-up days. To be conservative, we used warm-up days of 28 days [27].

Consequently, we obtained energy usage data for each permutation of factors. In order to understand the ranking of the factors, we used an N-way analysis of variance (ANOVA) to statistically analyze the influence of each factor. The application of ANOVA for studying the impact of various factors on buildings energy consumption was studied and recommended by authors in [28]. Through ranking the factors, we quantified how each factor contributes to the overall energy consumption of the HVAC system. We also calculated the normalized standard deviation in the feature domain of each factor. The percentile helps us to better understand the influence of each factor. At this point in our methodology, we excluded the weekends and holidays due to the fact that systems in these days are either off or operated in fewer hours. We then calculated the optimal annual control parameters (i.e., setpoints and deadbands) for each building size and climate, along with their potential energy savings. In order to calculate the optimal setpoint in each climate and size permutation, we calculated the summation of annual energy consumptions for buildings at each control parameter, and then searched the minimum total energy consumption across the control parameters. We then calculated the energy savings with respect to the baseline control parameter (i.e., setpoint: $22.5^{\circ} \mathrm{C}$, and deadband: $3 \mathrm{~K}$ ).

In addition to the derivation of optimal annual control parameters, in a previous study, we observed that the selection of setpoints with respect to outdoor temperatures can lead to a higher energy efficiency in buildings [29]. Therefore, in this study, we specifically focused on daily optimal control parameters (i.e., setpoints and deadbands), including the potential energy savings with respect to outdoor temperatures and their relationships with climates, construction categories and building sizes with optimal daily control parameters. To calculate the daily optimal control parameter, we designed an algorithm that 
searched through all simulation outputs to find the control parameters with the minimum energy use in each day. As the baseline, daily energy consumptions with the baseline control parameter were also calculated and stored. Accordingly, annual energy consumptions with different combinations of factors could be recalculated based on daily optimal set points and baseline control parameters. A new binary variable, which represented whether daily control parameter is the optimal one or the baseline is, was generated and replaced the original numeric control parameter variable in ANOVA. The new results of ANOVA showed how daily optimal control parameter impacted the energy use. Optimal control parameters with corresponding outdoor temperatures were then plotted to study the optimization patterns.

Building related factors, such as building size and construction category, might also influence the daily optimal setpoints. We are specifically interested in generalizing the daily setpoint selection across such factors. In other words, building sizes and construction categories might be significant to the selection of daily optimal setpoints. To investigate, we calculated the statistical significance of building size and construction category in each climate. The proportion of significant cases indicated whether it is reasonable to make a generalization. The generalization would lead to creating guidelines of control parameter selection as a function of outdoor temperature solely.

Finally, we calculated the energy savings from daily optimal setpoints with respect to the baseline (standard setpoint of $22.5^{\circ} \mathrm{C}$ and deadband of $3 \mathrm{~K}$ ). These savings were the maximum potential savings from selecting optimal daily setpoints. We also presented the energy savings of optimal daily setpoints along with the optimal annual setpoints, which covered all possible generalizations of factors, with respect to the outdoor temperatures. The tables and figures presented in this paper can potentially be used as guidelines for operation of a building's HVAC system. In addition, potential savings can help building stakeholders to decide on whether to pursue an energy saving technique which focuses on optimal control parameter selection.

\section{SIMULATION MODELS AND PROCEDURES}

U.S. DOE has released a set of commercial reference building energy simulation models (EnergyPlus models) in order to provide descriptions for whole building energy simulation analysis. There are 16 different types of buildings in 16 different climates (the most populous cities in each climate zone are presented in Table 1) constructed in three different categories of age (i.e., New construction (after 2004), Existing buildings (after 1980 - before 2004), Existing buildings (before 1980)) that represent about 70\% of commercial buildings in the United States [14]. These cities are most populated cities in each climate zone presented in Figure 1. 


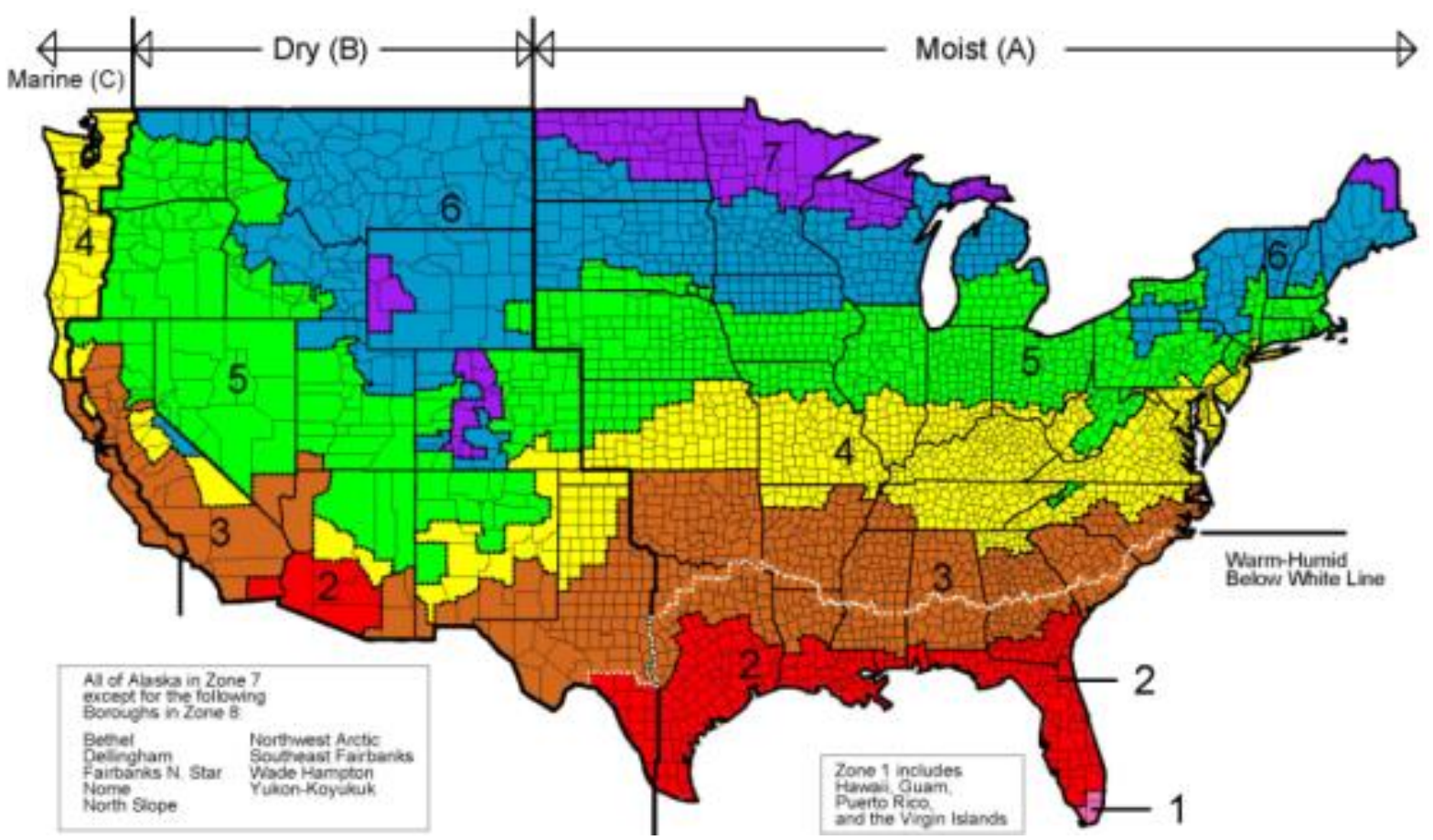

Figure 1. Climate zone classification ([30])

Construction materials and equipment parameters of the models in different construction categories were set based on ASHRAE standards. ASHRAE Standards 90.1-2004 (ASHRAE 2004a), 62.1-2004 (ASHRAE 2004b), and 62-1999 (ASHRAE 1999) were for new construction and Standard 90.1-1989 (ASHRAE 1989) for existing buildings (after 1980 - before 2004). Three of DOE's national laboratories (i.e., NREL, PNNL, and LBNL) performed research to determine the remaining model inputs [14].

In this paper, we specifically focus on office buildings in consideration of the fact that office buildings have the largest share of commercial building stock in the United States both in term of number $(18 \%)$ and floor space (18\%) [31]. In addition, office buildings have 38\% of total workers in commercial buildings [31]. The DOE divides office building models into three sizes based on the number of floors (small as 1 floor, medium as 2-4 floors, and large as more than 4 floors). The small, medium, and large reference office buildings have 1, 3, and 12 floors, respectively. Table 2 summarizes features of office building models with different sizes, and Figure 2 demonstrates building geometries of different sizes.

Table 2. Features of the different sizes of the office buildings [14]

\begin{tabular}{c|c|c|c}
\hline Feature & Small & Medium & Large \\
\hline No. of floors & 1 & 3 & 12 \\
\hline No. of elevators & 0 & 2 & 12 \\
\hline Total floor area $\left(\mathrm{m}^{2}\right)$ & 511 & 4,982 & 46,320 \\
\hline Aspect ratio & 1.5 & 1.5 & 3.5 \\
\hline Floor-to-floor height & 3.05 & 2.96 & 2.74 \\
\hline $\begin{array}{c}\text { Floor-to- } \\
\text { Ceiling Height }\end{array}$ & 0.21 & 0.33 & 0.38 \\
\hline Glazing fraction & $\begin{array}{c}\text { Insulation entirely above } \\
\text { deck, } \\
\text { Roof Construction } \\
\text { joist: roof insulation }+\end{array}$ & $\begin{array}{c}\text { Insulation entirely } \\
\text { above deck, } \\
\text { Built-up roof: } \\
\text { roof membrane }+\end{array}$ & $\begin{array}{c}\text { Insulation entirely } \\
\text { above deck, } \\
\text { Built-up roof: roof } \\
\text { membrane + Roof }\end{array}$ \\
\hline
\end{tabular}




\begin{tabular}{|c|c|c|c|}
\hline & $1.6 \mathrm{~cm}$ gypsum board & $\begin{array}{l}\text { roof insulation + } \\
\text { metal decking }\end{array}$ & $\begin{array}{c}\text { insulation + metal } \\
\text { decking }\end{array}$ \\
\hline Wall Constructions & Steel frame, Mass, Mass & Steel frame & Mass \\
\hline Exterior Walls & $\begin{array}{l}\text { Wood-frame walls (2X4 } \\
40 \mathrm{sm} \mathrm{OC)} \\
2.5 \mathrm{~cm} \text { stucco }+1.6 \mathrm{~cm} \\
\text { gypsum board }+ \text { wall } \\
\text { Insulation }+1.6 \mathrm{~cm} \\
\text { gypsum board }\end{array}$ & $\begin{array}{l}\text { Steel-frame walls } \\
(2 \mathrm{X} 440 \mathrm{~cm} \mathrm{OC}) \\
1 \mathrm{~cm} \text { stucco+1.6cm } \\
\text { gypsum board + wall } \\
\text { Insulation+1.6cm. }\end{array}$ & $\begin{array}{l}\text { Pre-cast concrete } \\
\text { panel: } 20 \mathrm{~cm} \text { heavy- } \\
\text { weight concrete }+ \\
\text { wall Insulation }+ \\
1.3 \mathrm{~cm} \text { gypsum board }\end{array}$ \\
\hline Parking Lot Area $\left(\mathrm{m}^{2}\right)$ & 828 & 8,067 & 30,201 \\
\hline Heating & Furnace & Furnace & Boiler \\
\hline Cooling & $\begin{array}{c}\text { PACU (Packaged Air } \\
\text { Conditioning Unit) }\end{array}$ & PACU & MZ VAV \\
\hline Air Distribution & $\begin{array}{l}\text { SZ CAV (Single-Zone } \\
\text { Constant Air Volume) }\end{array}$ & $\begin{array}{c}\text { SZ CAV, MZ VAV } \\
\text { (MultiZone Variable } \\
\text { Air Volume) }\end{array}$ & MZ VAV \\
\hline Occupancy $\left(\mathrm{m}^{2} /\right.$ person $)$ & 18.6 & 18.6 & 18.6 \\
\hline
\end{tabular}

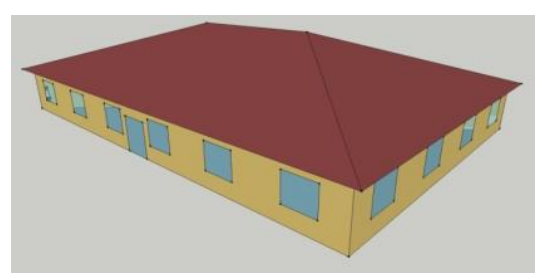

Small

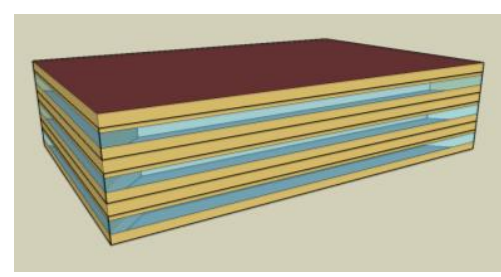

Medium

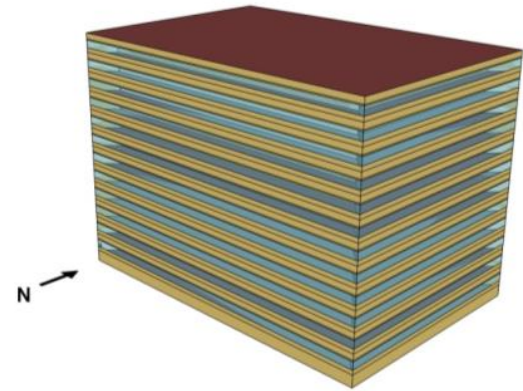

Large

Figure 2. Building geometries of different sizes

The reference building models are assigned different occupancy and operation schedules based on weekdays (HVAC system operations from 6:00 AM to 10:00 PM), Saturdays (HVAC system operations from 9:00 AM to 5:00 PM), and Sundays and holidays (HVAC system is off the entire day), which possibly has significant impacts on the overall energy consumption. Therefore, we integrated occupancy schedules into our analysis as a factor as described in Section 3. Further information about these office buildings can be found in [14,32]. Once the simulations were completed, we stored the results a CSV file and processed them by programing to add up hourly energy consumption and calculate the energy usage over the year. The simulation conditions (e.g., setpoint, deadband, city, construction category, size, occupancy schedule) were then stored in a vector and associated with the daily HVAC system energy consumption.

\section{RESULTS AND DISCUSSION}

The simulation results provided energy consumption over a year on an hourly basis. The daily HVAC system and the whole building energy consumption for a new construction (after 2004) in a sample city (i.e., Minneapolis, Minnesota) over a year (with elimination of the first 28 days as described in Section 3) for three building sizes with the baseline control parameters of $22.5{ }^{\circ} \mathrm{C}$ for the setpoint and $3 \mathrm{~K}$ for the deadband are presented in Figure 3. Whole building energy consumption includes all the electricity and gas used in the building (by lighting systems, HVAC system, and appliances). Figure 3 includes energy consumption for weekdays, weekends, and holidays. Consequently, there are days that HVAC system did not consume any electricity or gas. 


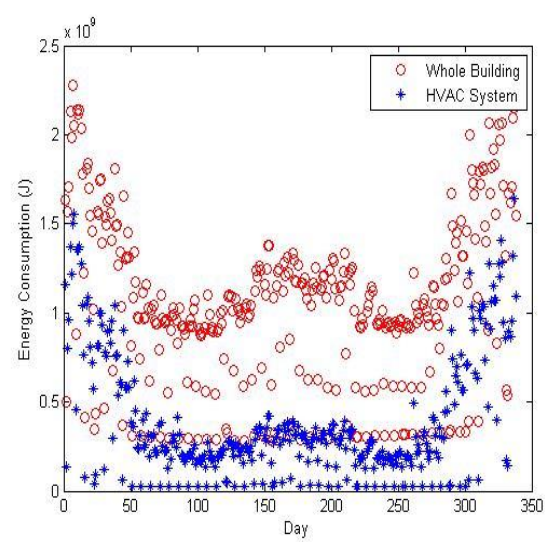

a

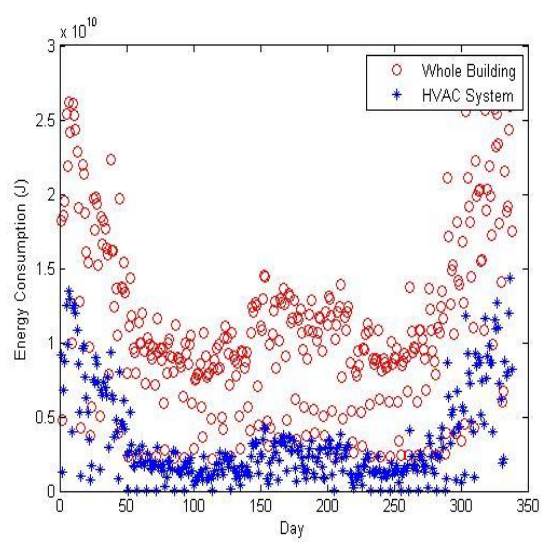

$\mathrm{b}$



$\mathrm{c}$

Figure 3. HVAC system and whole building energy consumption for $(a)$ small $(b)$ medium $(c)$ large office buildings built after 2004 in Minneapolis, Minnesota.

For a better presentation of daily energy consumption, we used average daily outdoor temperatures. Figure 4 presents the daily energy consumption of the three building sizes in different construction categories in Minneapolis, Minnesota with respect to the average daily outdoor temperatures over a year. The control parameters were $22.5{ }^{\circ} \mathrm{C}$ for the setpoint and $3 \mathrm{~K}$ for the deadband. In Figure 4, we compare daily HVAC energy consumption of different construction categories in order to understand how construction categories influence the energy consumption, using the baseline setting. As can be seen in Figure 4, the newer the building, the smaller the energy consumption in this climate.

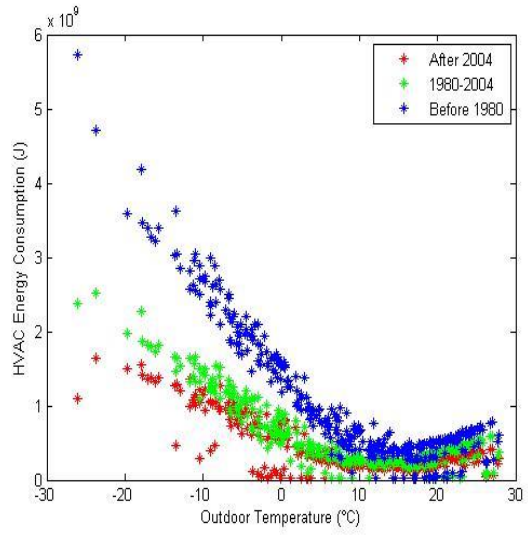

a

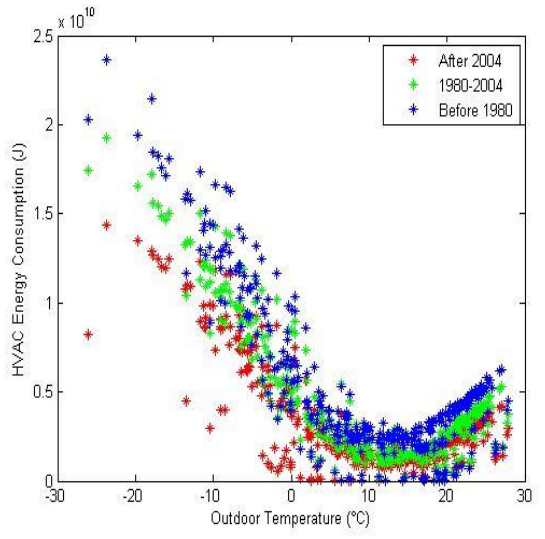

b

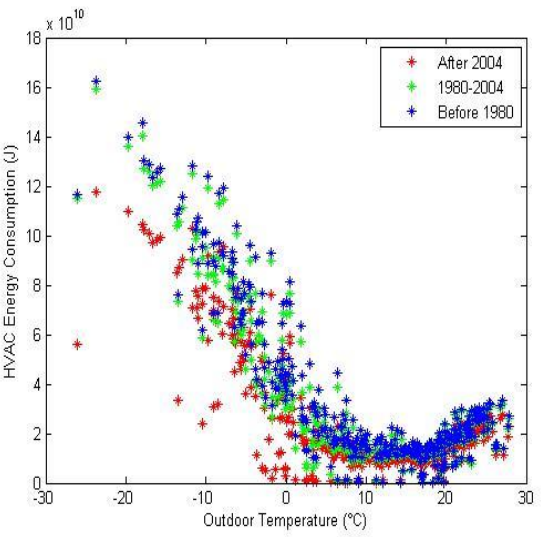

$\mathrm{c}$

Figure 4. HVAC energy consumption for different construction categories in the baseline setting for (a) small, (b) medium, and (c) large sizes in Minneapolis, Minnesota.

Then we simulated 7056 permutations of factors and performed an n-way ANOVA analysis on the results. An n-way ANOVA is used to analyze the differences among group means across several dimensions of variables. The p-value from an ANOVA analysis can hold values between 0 and 1 and it tests the null hypothesis that the data from all groups are drawn from populations with identical means. If p-value is larger than a threshold (e.g., 0.05), then we cannot conclude if the factor has resulted in any significant change in the means of the groups. On the other hand, if the p-value is smaller than a threshold (e.g., 0.05), we can reject the null hypothesis of indifferent means of the group with confidence (e.g., 0.95 probability) and take the factor having as a statistically significant influence on the means of the target variable. In this study, we set the threshold to 0.05 to find the factors that have an influence on the energy 
consumption with $95 \%$ probability. The $\mathrm{P}$ value is computed from the F-values and the degrees of freedom from the ANOVA analysis. The F value is the ratio of two mean square values of the groups. The larger the $\mathrm{F}$ value, the higher chance (probability) that the null hypothesis is false (i.e., the variation among group means could not have happened by chance) and the greater the importance of the factor on the target variable. The larger the F value, the greater the importance of the factor on the target variable. In addition to ANOVA analysis, we also calculated the standard deviations of energy consumption for each factor. The larger the deviation, the more impact of the factor have on the target variable. We also calculated the percentages of deviation to average energy consumption (normalized standard deviations) to make the results more understandable. Table 3 summarizes the results of the ANOVA analysis for the HVAC system. As is shown in Table 3, building size is the most influential factor on the energy consumption, while the setpoint has the least impact. Both the p-value and the standard deviation demonstrate this point. Next, we studied the optimal control parameters, which may differ from climate to climate, even from day to day.

Table 3. N-way ANOVA and normalized standard deviation results for different factors

\begin{tabular}{cccc}
\hline Factor & F & p-value & $\begin{array}{c}\text { Standard deviation (Normalized standard } \\
\text { deviation) }\end{array}$ \\
\hline Setpoint & 2.7 & 0.0127 & $0.39 \times 10^{9}(2.81 \%)$ \\
Deadband & 172.7 & $\sim 0$ & $3.13 \times 10^{9}(22.49 \%)$ \\
Construction & 398.0 & $\sim 0$ & $3.11 \times 10^{9}(22.35 \%)$ \\
category & 542.2 & $\sim 0$ & $3.63 \times 10^{9}(26.08 \%)$ \\
Occupancy schedule & 559.2 & $\sim 0$ & $8.51 \times 10^{9}(61.18 \%)$ \\
Climate & 15480.1 & $\sim 0$ & $19.40 \times 10^{9}(139.38 \%)$ \\
Size & & &
\end{tabular}

We first searched annual optimal setpoints for each combination of climate and building size, as well as those for all building sizes, and calculated the energy savings with respect to the baseline, which are shown in Table 4. The hotter the climate, the higher the annual optimal setpoints. In addition, buildings in hotter climates result in more energy savings by choosing annual optimal setpoints due to the fact that HVAC system continuously compensates for occupants' heat production and the heat transfers from the outdoor environment. Compared to the large office buildings, small buildings have higher potentials to save energy and improve efficiency through setpoint selection due to the fact that control parameters have larger impacts on the HVAC energy consumption in small buildings. Based on the description provided by the DOE, the larger the office building models, the smaller perimeter zones to internal zones ratio, which results in a smaller impact of control parameter selection.

Table 4. Annual optimal setpoint for each climate, and each size, generalized by category and deadband - each column is color-coded for maximum (green) to minimum (red)

\begin{tabular}{ccccc|c|c|c}
\hline & \multicolumn{2}{c}{ Small } & \multicolumn{2}{c}{ Medium } & \multicolumn{2}{c}{ Large } \\
\hline Climate & $\begin{array}{c}\text { Optimal } \\
\text { Setpoint } \\
\left({ }^{\circ} \mathrm{C}\right)\end{array}$ & $\begin{array}{c}\text { Saving } \\
(\%)\end{array}$ & $\begin{array}{c}\text { Optimal } \\
\text { Setpoint } \\
\left({ }^{\circ} \mathrm{C}\right)\end{array}$ & $\begin{array}{c}\text { Saving } \\
(\%)\end{array}$ & $\begin{array}{c}\text { Optimal } \\
\text { Setpoint } \\
\left({ }^{\circ} \mathrm{C}\right)\end{array}$ & $\begin{array}{c}\text { Saving } \\
(\%)\end{array}$ \\
\hline Miami, Florida (1A) & 25.5 & 36.72 & 25.5 & 20.15 & 24.5 & 2.58 \\
Houston, Texas (2A) & 25.5 & 13.06 & 25.5 & 13.78 & 23.5 & 2.33 \\
Phoenix, Arizona (2B) & 25.5 & 16.34 & 25.5 & 16.6 & 24.5 & 5.18 \\
Atlanta, Georgia (3A) & 23.5 & 2.73 & 24.5 & 6.94 & 23.5 & 2.78 \\
Los Angeles, California (3B) & 24.5 & 13.64 & 25.5 & 16.41 & 24.5 & 5.95
\end{tabular}




\begin{tabular}{cc|c|c|c|c|c} 
Las Vegas, Nevada (3B) & 24.5 & 8.06 & 25.5 & 14.68 & 24.5 & 5.66 \\
San Francisco, California (3C) & 22.5 & 0 & 23.5 & 0.49 & 23.5 & 1.09 \\
Baltimore, Maryland (4A) & 22.5 & 0 & 23.5 & 1.43 & 23.5 & 2.84 \\
Albuquerque, New Mexico & 22.5 & 0 & 24.5 & 4.75 & 23.5 & 3.13 \\
(4B) & 21.5 & 3.34 & 21.5 & 0.43 & 23.5 & 1.36 \\
Seattle, Washington (4C) & 21.5 & 1.73 & 22.5 & 0 & 23.5 & 0.72 \\
Chicago, Illinois (5A) & 21.5 & 0.99 & 22.5 & 0 & 23.5 & 1.58 \\
Denver, Colorado (5B) & 21.5 & 2.53 & 21.5 & 0.57 & 22.5 & 0 \\
Minneapolis, Minnesota (6A) & 20.5 & 4.26 & 21.5 & 0.55 & 23.5 & 0.01 \\
Helena, Montana (6B) & 20.5 & 6.64 & 20.5 & 3.31 & 22.5 & 0 \\
Duluth, Minnesota (7) & 19.5 & 9.52 & 19.5 & 5.69 & 19.5 & 1.38 \\
Fairbanks, Alaska (8) & & & & & &
\end{tabular}

To study the impact of daily optimal control parameters, we used the algorithm described in Section 3 to find daily optimal setpoints and deadbands, as well as the associated energy consumptions. In addition, we extracted and saved the baseline setpoint $\left(22.5^{\circ} \mathrm{C}\right)$ and deadband $(3 \mathrm{~K})$, as well as the energy consumptions. Therefore, we created new binary variables representing the daily optimal setpoint and deadband, and replaced the original two in ANOVA. Table 5 and Table 6 present the result of ANOVA analysis with the optimal control parameters. The optimal control parameters are found to be the most influential factors.

Table 5. N-way ANOVA for daily optimal/baseline setpoint and other factors

\begin{tabular}{ccc}
\hline Factor & F & p-value \\
\hline Optimal Setpoint & 474 & 0 \\
Deadband & 0.01 & 1 \\
Construction category & 0.86 & 0.4224 \\
Climate & 0.1 & 1 \\
Size & 9.83 & 0.001 \\
\hline
\end{tabular}

Table 6. N-way ANOVA for daily optimal/baseline deadband and other factors

\begin{tabular}{ccc}
\hline Factor & $\mathrm{F}$ & $p$-value \\
\hline Optimal Deadband & 472.45 & 0 \\
Setpoint & 0.01 & 1 \\
Construction category & 0.86 & 0.7782 \\
Climate & 0.13 & 1 \\
Size & 1.69 & 0.1852 \\
\hline
\end{tabular}

Although both daily optimal setpoints and deadbands significantly affect building energy efficiency, it is important to study their relationship with the outdoor environment and other factors (e.g., construction category, size, and etc.). Figure 5 shows the daily optimal setpoints plotted with respect to outdoor temperatures for all climates for a sample permutation of factors (new construction (after 2004) and small size). There is a strong correlation between the daily optimal setpoints and outdoor temperatures, as the hotter the outdoor environment, the higher the setpoint should be to save energy. A similar relationship also exists across all permutations of factors. 

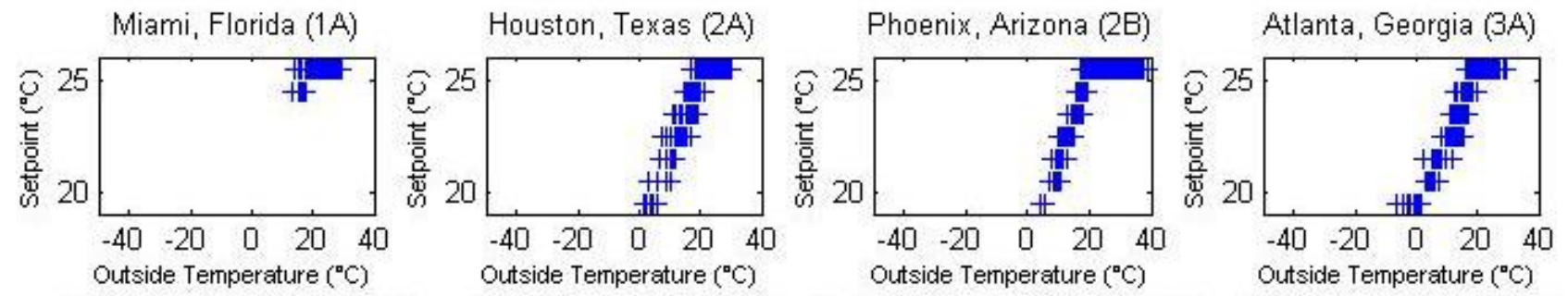

Los Angeles, California (3B)

Las Vegas, Nevada (3B)

San Francisco, California (3C)

Baltimore, Maryland (4A)
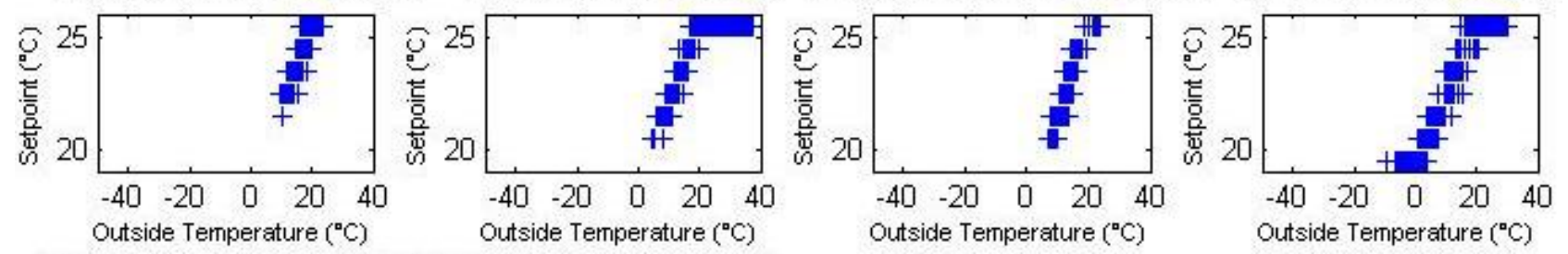

Albuquerque, New Mexico (4B) Seattle, Washington (4C)


Denver, Colorado (5B)

Minneapolis, Minnesota (6A)
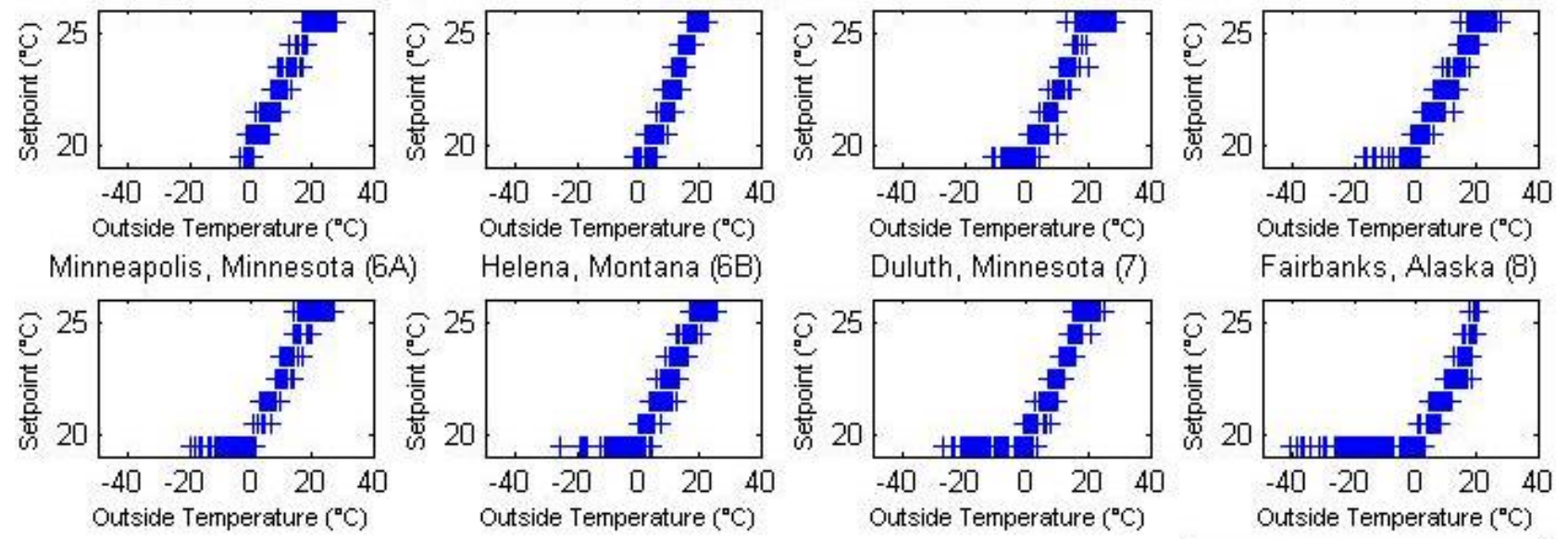

Fairbanks, Alaska (8)



+ Daily Optimal Setpoint

Figure 5. Relationships between daily optimal setpoints and outdoor temperatures for all climates, baseline deadband ( $3 K)$, new construction and small size office building

As a comparison, the relationships between daily optimal deadbands and outdoor temperatures for the same building type (new construction and small size office building) for all climates are also plotted, and presented in Figure 6. Contrast to the setpoints, the daily optimal deadbands hardly show any correlation to the outdoor temperature and the largest deadband (6K) is the optimal choice. This finding is reasonable as a large deadband means more tolerance of the variation of indoor temperature, resulting in less time an HVAC system operates and consequently, consumes less energy. 

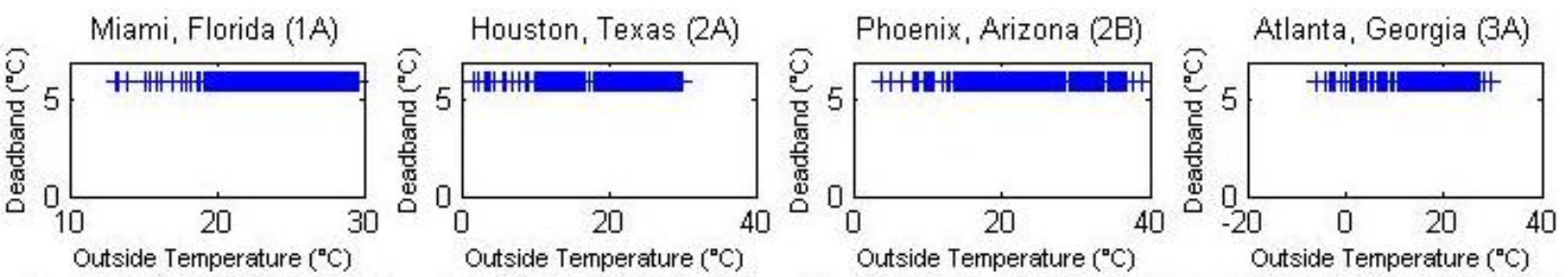

Los Angeles, California (3B)
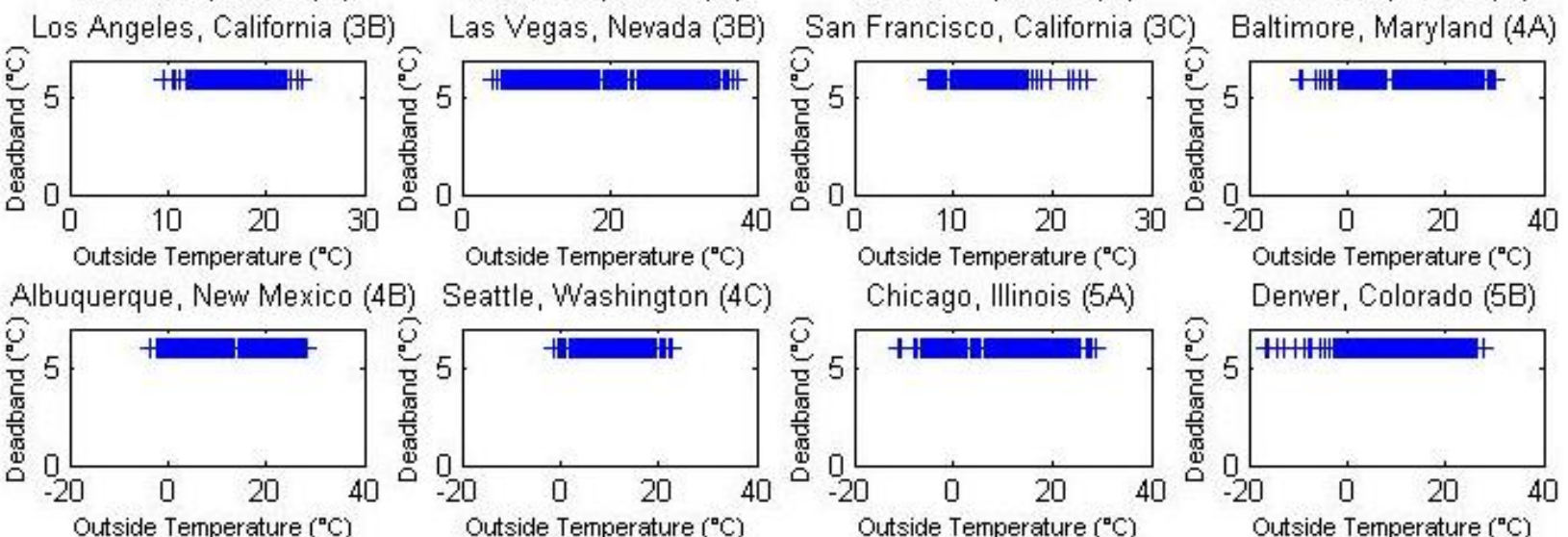

Denver, Colorado (5B)



Helena, Montana (6B)
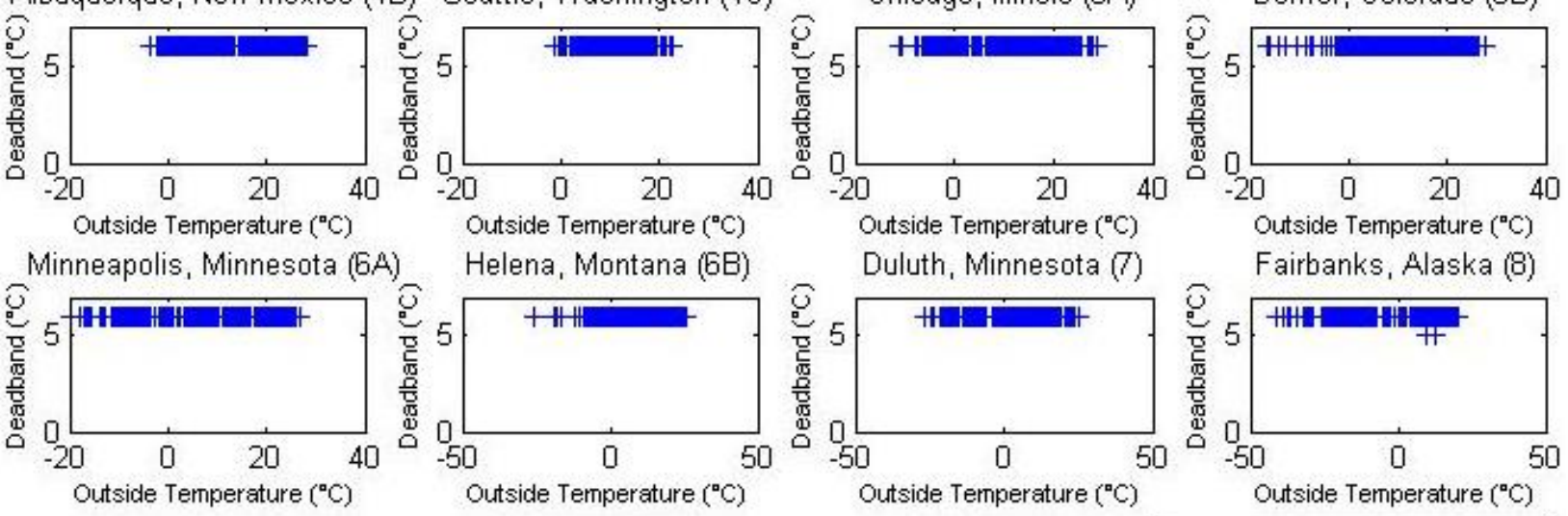

Fairbanks, Alaska (8)

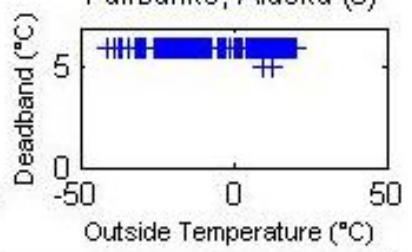

+ Daily Optimal Deadband

Figure 6. Relationships between daily optimal deadbands and outdoor temperatures for all climates, baseline setpoint $\left(22.5^{\circ} \mathrm{C}\right)$, new construction and small size office buildings

Besides the outdoor temperature, we also studied the impact of construction category and building size on daily optimal setpoints. Generally, the building size is significantly influential while the construction category is not. We performed one-way ANOVA of optimal setpoints and construction categories for each combination of climate and building size. Out of the 48 permutations, 30 of them showed that the impact of construction category on optimal setpoints is not significant with the average $p$ value of 0.31 . Therefore, we used the average results of all construction categories herein after for the presentation of optimal setpoint selection.

Figure 7 (a-c) illustrate daily optimal setpoints and their energy savings with respect to outdoor temperatures for all climates. Each figure represents one building size and has a fixed deadband of $0 \mathrm{~K}$. Figure $7 \mathrm{~d}$ shows daily optimal setpoints for all sizes. As can be seen in these figures, the higher the outdoor temperature, the higher the optimal setpoint. Compared to small buildings, large buildings tend to have higher optimal setpoints, possibly because of the smaller impact of outdoor conditions and larger influence of building systems and occupants. 


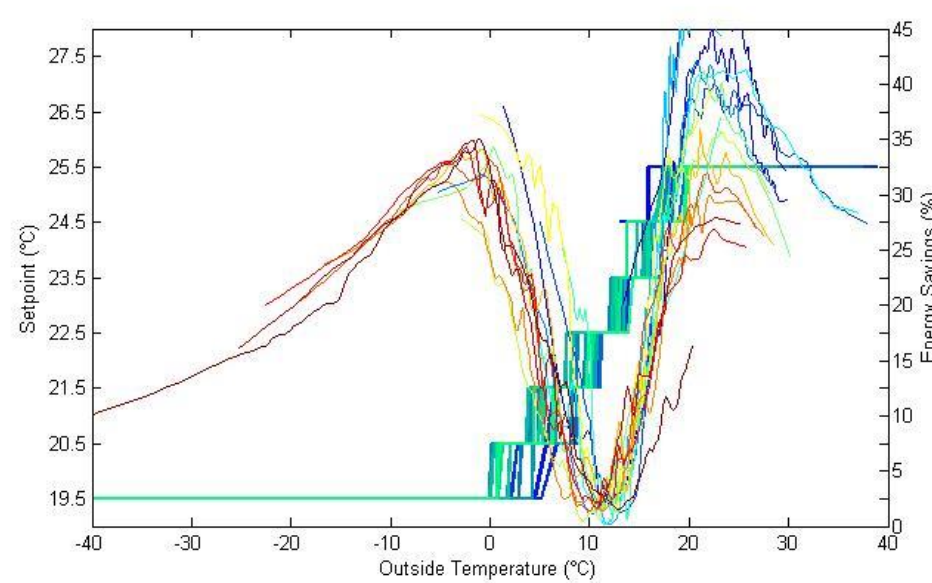

(a)

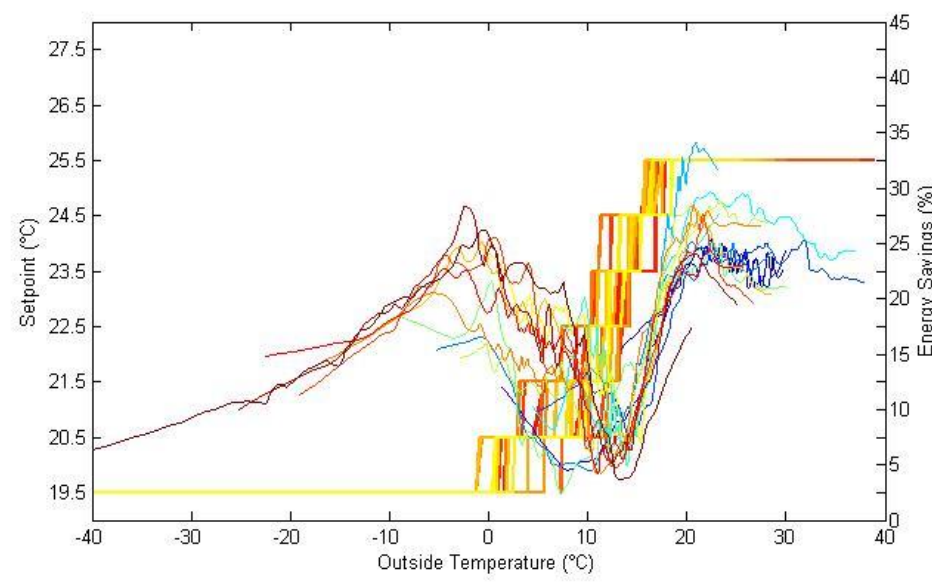

(c)
Daily Optimal Setpoint

- Miami, Florida (1A)

Houston, Texas (2A)

- Phoenix, Arizona (2B)

Atlanta, Georgia (3A)

Los Angeles, California (3B)

Las Vegas, Nevada (3B)

- San Francisco, California (3C) Baltimore, Maryland (4A)

Albuquerque, New Mexico (4B)

Seattle, Washington (4C)

Chicago, Illinois (5A)

- Denver, Colorado (5B)

- Minneapolis, Minnesota (6A)

- Helena, Montana (6B)

Duluth, Minnesota (7)

_ Fairbanks, Alaska (8)

Energy Saving

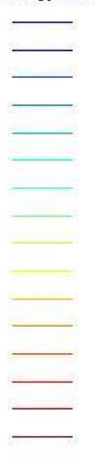

Daily Optimal Setpoint

Energy Saving

- Miami, Florida (1A)

- Houston, Texas (2A)

-Phoenix, Arizona (2B)

-Atlanta, Georgia (3A)

Los Angeles, California (3B)

Las Vegas, Nevada (3B)

- San Francisco, California (3C)

Baltimore, Maryland (4A)

- Albuquerque, New Mexico (4B)

Seattle, Washington (4C)

Chicago, Illinois (5A)

- Denver, Colorado (5B)

- Minneapolis, Minnesota (6A)

- Helena, Montana (6B)

Duluth, Minnesota (7)

Fairbanks, Alaska (8)



(b)

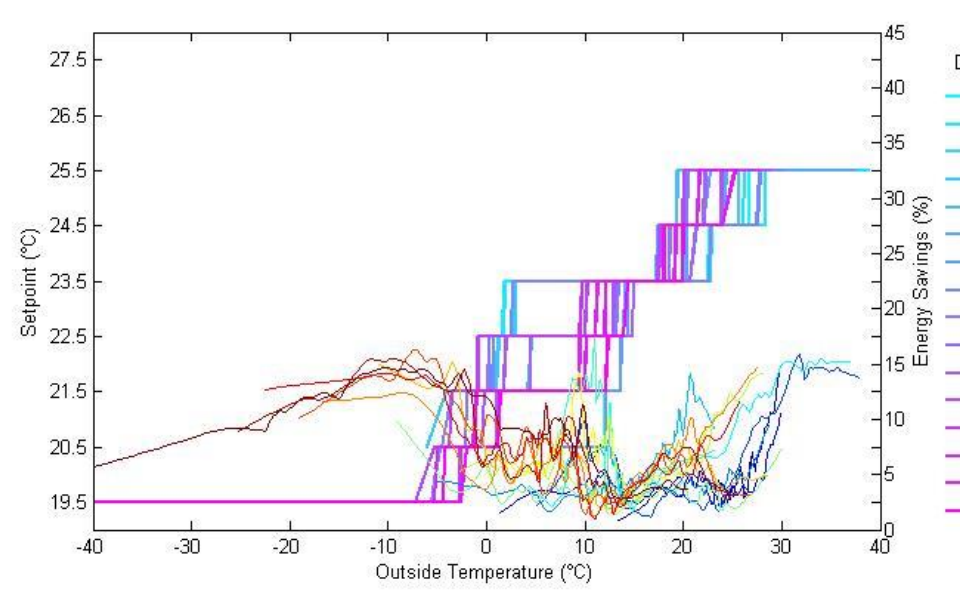

Daily Optimal Setpoint

Miami, Florida (1A)

Houston, Texas (2A)

Phoenix, Arizona (2B)

- Atlanta, Georgia (3A)

Los Angeles, California (3B)

Las Vegas, Nevada (3B)

San Francisco, California (3C)

Baltimore, Maryland (4A)

Albuquerque, New Mexico (4B)

Seattle, Washington (4C)

Chicago, Illinois (5A)

Denver, Colorado (5B)

Minneapolis, Minnesota (6A)

Helena, Montana (6B)

Duluth, Minnesota (7)

Fairbanks, Alaska (8)
Energy Saving

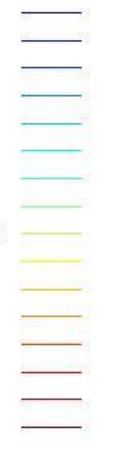




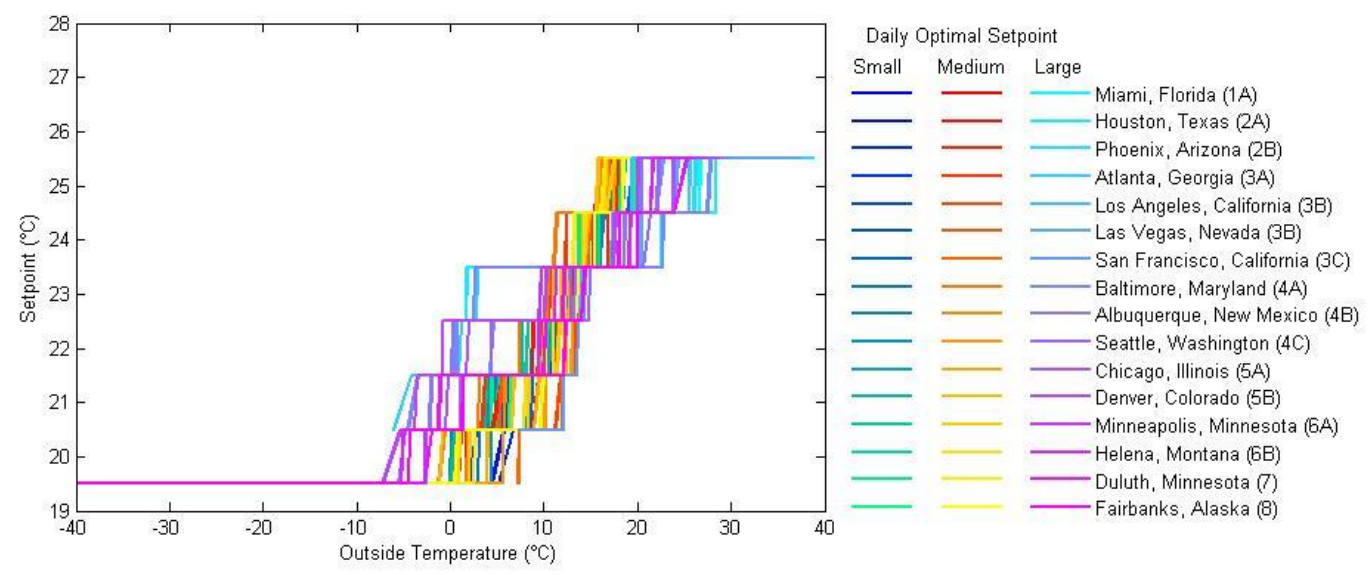

(d)

Figure 7. Relationship between daily optimal setpoint, energy savings and outdoor temperature for all climates, (a) small, (b) medium, (c) large size, and deadband as $3 K$, (d) relationship between daily optimal setpoint and outdoor temperature for all climates, all sizes, generalized by construction and deadband as $3 \mathrm{~K}$

Table 7 summarizes the energy savings by selecting daily optimal setpoints for a whole year for each climate and building size. The results are presented as percentage difference between energy consumptions with optimal setpoints and the baseline, averaged for all categories and deadbands. As is shown in Table 7, the pattern of energy savings among different climates and building sizes is consistent with the annual optimal setpoints. However, daily optimal setpoints have more potential to improve building energy efficiency, especially for large buildings. For small, medium and large office buildings, selecting daily optimal setpoints would lead to $10.09-37.03 \%, 11.43-21.01 \%$, and $6.78-11.34 \%$ savings, respectively, depending on the climate. In addition, in climates with relatively cooler weather (e.g., Baltimore, Maryland (4A), Albuquerque, New Mexico (4B), Seattle, Washington (4C), etc.), selection of daily optimal setpoints would result in relatively higher energy savings compared to annual optimal setpoints.

Table 7. Energy savings of daily optimal setpoint for each climate and size, averaged by category and deadband, and the \% improvements compared to annual optimal setpoints - the table is color-coded for maximum (green) to minimum (red) percentages

\begin{tabular}{|c|c|c|c|c|c|c|}
\hline \multirow[t]{2}{*}{ Climate } & \multicolumn{3}{|c|}{$\begin{array}{c}\% \text { saving } \\
\text { compared to baseline }\end{array}$} & \multicolumn{3}{|c|}{$\begin{array}{c}\% \text { improvement } \\
\text { compared to annual optimal }\end{array}$} \\
\hline & Small & Medium & Large & Small & Medium & Large \\
\hline Miami, Florida (1A) & 37.03 & 20.84 & 6.78 & 0.31 & 0.69 & 4.2 \\
\hline Houston, Texas (2A) & 27.85 & 18.36 & 6.86 & 14.79 & 4.58 & 4.53 \\
\hline Phoenix, Arizona (2B) & 25.8 & 19.47 & 9.81 & 9.46 & 2.87 & 4.63 \\
\hline Atlanta, Georgia (3A) & 23.2 & 16.78 & 8.25 & 20.47 & 9.84 & 5.47 \\
\hline Los Angeles, California (3B) & 23.81 & 21.01 & 9.79 & 10.17 & 4.6 & 3.84 \\
\hline Las Vegas, Nevada (3B) & 22.36 & 20.13 & 10.56 & 14.3 & 5.45 & 4.9 \\
\hline $\begin{array}{c}\text { San Francisco, California } \\
(3 \mathrm{C})\end{array}$ & 10.09 & 11.43 & 8.08 & 10.09 & 10.94 & 6.99 \\
\hline Baltimore, Maryland (4A) & 22.06 & 16.07 & 9.51 & 22.06 & 14.64 & 6.67 \\
\hline $\begin{array}{c}\text { Albuquerque, New Mexico } \\
\text { (4B) }\end{array}$ & 18.01 & 17.82 & 10.3 & 18.01 & 13.07 & 7.17 \\
\hline Seattle, Washington (4C) & 20.74 & 15.94 & 9.97 & 17.4 & 15.51 & 8.61 \\
\hline
\end{tabular}




\begin{tabular}{c|ccc|ccc} 
Chicago, Illinois (5A) & 21.42 & 17.84 & 11.28 & 19.69 & 17.84 & 10.56 \\
Denver, Colorado (5B) & 16.39 & 15.9 & 11 & 15.4 & 15.9 & 9.42 \\
Minneapolis, Minnesota (6A) & 20.16 & 16.69 & 11.34 & 17.63 & 16.12 & 11.34 \\
Helena, Montana (6B) & 17.87 & 15.14 & 11.15 & 13.61 & 14.59 & 11.14 \\
Duluth, Minnesota (7) & 17.29 & 15.26 & 11.3 & 10.65 & 11.95 & 11.3 \\
Fairbanks, Alaska (8) & 14.08 & 12.28 & 9.72 & 4.56 & 6.59 & 8.34 \\
\hline
\end{tabular}

In Table 8, we calculated the energy savings if deadbands were selected optimally within a range of 0 $\mathrm{K}$ to $1,23,4,5$, and $6 \mathrm{~K}$ (as we found optimal values are always the highest) with respect to the baseline deadband $(3 \mathrm{~K})$ at each day. In Table 9 , we calculated the energy savings if the setpoints were selected optimally within a range at $22.5 \pm 1{ }^{\circ} \mathrm{C}, 22.5 \pm 2{ }^{\circ} \mathrm{C}$, and $22.5 \pm 3{ }^{\circ} \mathrm{C}$ with respect to the baseline setpoint $\left(22.5^{\circ} \mathrm{C}\right)$.

Table 8. Percentage energy savings through adjusting deadband selection domain in daily optimal selection - the table is color-coded for maximum (green) to minimum (red) percent savings

\begin{tabular}{|c|c|c|c|c|c|c|c|}
\hline Climate & $0 \mathrm{~K}$ & $1 \mathrm{~K}$ & $2 \mathrm{~K}$ & $3 \mathrm{~K}$ & $4 \mathrm{~K}$ & $5 \mathrm{~K}$ & $6 \mathrm{~K}$ \\
\hline Miami, Florida (1A) & -42.1 & -16.2 & -5.6 & 0 & 3.3 & 5.2 & 6.7 \\
\hline Houston, Texas (2A) & -57.7 & -27.3 & -10.7 & 0 & 7.2 & 12.3 & 16 \\
\hline Phoenix, Arizona (2B) & -62.6 & -28.9 & -11.1 & 0 & 8.1 & 14.1 & 18.8 \\
\hline Atlanta, Georgia (3A) & -69.6 & -34.3 & -13.5 & 0 & 9.2 & 15.6 & 20.4 \\
\hline Los Angeles, California (3B) & -117.5 & -55.8 & -20.8 & 0 & 13.8 & 23 & 29 \\
\hline Las Vegas, Nevada (3B) & -75.4 & -35.7 & -13.9 & 0 & 10 & 17.5 & 23.2 \\
\hline San Francisco, California (3C) & -133.2 & -69.9 & -27.9 & 0 & 20.4 & 35.4 & 46.1 \\
\hline Baltimore, Maryland (4A) & -66.4 & -34.3 & -13.8 & 0 & 9.6 & 16.4 & 21.2 \\
\hline Albuquerque, New Mexico & & & & & & & \\
\hline$(4 \mathrm{~B})$ & -81.2 & -40.6 & -16.2 & 0 & 11.4 & 19.5 & 25.4 \\
\hline Seattle, Washington (4C) & -96.7 & -52.8 & -21.7 & 0 & 16 & 27.8 & 36.3 \\
\hline Chicago, Illinois (5A) & -59.8 & -30 & -11.6 & 0 & 7.7 & 12.9 & 16.5 \\
\hline Denver, Colorado (5B) & -78.1 & -39.4 & -15.4 & 0 & 10.6 & 18 & 23 \\
\hline Minneapolis, Minnesota (6A) & -47 & -23.7 & -9.3 & 0 & 6.2 & 10.6 & 13.5 \\
\hline Helena, Montana (6B) & -63.9 & -33 & -13.1 & 0 & 9.1 & 15.3 & 19.5 \\
\hline Duluth, Minnesota (7) & -43.4 & -23.1 & -9.2 & 0 & 6.5 & 11 & 14.2 \\
\hline Fairbanks, Alaska (8) & -24.6 & -13.4 & -5.6 & 0 & 4.2 & 7.2 & 9.6 \\
\hline Average & -70.0 & -34.9 & -13.7 & 0 & 9.6 & 16.4 & 21.2 \\
\hline
\end{tabular}

As can be seen in Table 8, reducing the deadband selection range to $0 \mathrm{~K}$, would considerably increase the energy usage: $24.6 \%$ in Fairbanks, Alaska (8) (minimum) to $133.2 \%$ in San Francisco, California (3C) (maximum) with an average of $70.0 \%$ across all climates. When we allow deadbands to be selected between 0 and $1 \mathrm{~K}$, the increase in usage considerably decreases: 13.4\% in Fairbanks, Alaska (8) (minimum) to $69.9 \%$ in San Francisco, California (3C) (maximum) with an average of $34.9 \%$ across all climates. Since optimal deadbands are always the highest, when we relax the deadbands to hold any value between $0,1,2$, and $3 \mathrm{~K}$, there are no savings. On the other hand, adding a $4 \mathrm{~K}$ deadband to the selection pool would lead to energy savings: $3.3 \%$ in Miami, Florida (1A) (minimum) to $20.4 \%$ in San Francisco, California (3C) (maximum) with an average of $9.6 \%$ across all climates. By relaxing the deadband to hold any value between 0 to $6 \mathrm{~K}$, the energy savings considerably increases: $6.7 \%$ in and Miami, Florida (1A) (minimum) to $46.1 \%$ in San Francisco, California (3C) (maximum) with an average of $21.2 \%$ across all climates. 
Table 9. Percentage energy savings through adjusting setpoint selection range in daily optimal selection $\left(22.5^{\circ} \mathrm{C}\right.$ is the baseline operation) - the table is color-coded for maximum (green) to minimum (red)

\begin{tabular}{ccccc}
\multicolumn{5}{c}{ percent savings } \\
\hline Climate & $22.5{ }^{\circ} \mathrm{C}$ & $22.5 \pm 1{ }^{\circ} \mathrm{C}$ & $22.5 \pm 2{ }^{\circ} \mathrm{C}$ & $22.5 \pm 3{ }^{\circ} \mathrm{C}$ \\
\hline Miami, Florida (1A) & 0 & 8.4 & 15.6 & 21.9 \\
Houston, Texas (2A) & 0 & 7.7 & 13.6 & 17.7 \\
Phoenix, Arizona (2B) & 0 & 7.8 & 14 & 18.7 \\
Atlanta, Georgia (3A) & 0 & 7.5 & 12.5 & 16 \\
Los Angeles, California (3B) & 0 & 9.8 & 15.5 & 18.9 \\
Las Vegas, Nevada (3B) & 0 & 8.2 & 13.9 & 18.1 \\
San Francisco, California (3C) & 0 & 6.4 & 9.4 & 11.1 \\
Baltimore, Maryland (4A) & 0 & 7.6 & 12.6 & 15.7 \\
Albuquerque, New Mexico (4B) & 0 & 7.5 & 12.3 & 15.5 \\
Seattle, Washington (4C) & 0 & 8.5 & 13.6 & 16.3 \\
Chicago, Illinois (5A) & 0 & 7.8 & 13.4 & 17.3 \\
Denver, Colorado (5B) & 0 & 7.2 & 12 & 14.9 \\
Minneapolis, Minnesota (6A) & 0 & 7 & 12.4 & 16.8 \\
Helena, Montana (6B) & 0 & 7.1 & 12.1 & 15.6 \\
Duluth, Minnesota (7) & 0 & 6.3 & 11.3 & 15.4 \\
Fairbanks, Alaska (8) & 0 & 4.7 & 8.8 & 12.5 \\
Average & 0 & 7.5 & 12.7 & 16.4 \\
\hline
\end{tabular}

As can be seen in Table 9, allowing the setpoint to be selected optimally from the range of $22.5 \pm 1{ }^{\circ} \mathrm{C}$ (i.e., $21.5^{\circ} \mathrm{C}, 21.5^{\circ} \mathrm{C}, 23.5^{\circ} \mathrm{C}$ ) at each day would result in the energy savings of: $4.7 \%$ in Fairbanks, Alaska (8) (minimum) to $9.8 \%$ in Los Angeles, California (3B) (maximum) with an average of $7.5 \%$ across all climates. Relaxing the setpoint selection range to $22.5 \pm 2{ }^{\circ} \mathrm{C}$ would improve the energy savings of: $9.4 \%$ in San Francisco, California (3C) (minimum) to $15.6 \%$ in Miami, Florida (1A) (maximum) with an average of $12.7 \%$ across all climates. Further relaxing the range to $22.5 \pm 3{ }^{\circ} \mathrm{C}$ would improve the energy savings to $11.1 \%$ in San Francisco, California (3C), (minimum) and $21.9 \%$ in Miami, Florida (1A) (maximum) with an average of $16.4 \%$ across all climates.

\section{LIMITATIONS AND FUTURE WORK}

In this paper, we followed a systematic approach to study the effects of HVAC control parameters (i.e., setpoints and deadbands), occupancy schedules, climate and building related factors on building energy consumption. The optimal control parameters were driven with respect to the outdoor temperature for all permutations of other factors. Specifically, occupancy schedules were fixed throughout the year, which were defined in the reference building models by the DOE. However, occupancy presence, behaviors and associated heat loads might vary during occupied times [33-35] and therefore, a future study should use more realistic occupancy schedules. As explained in section 4, we used a conservative warm-up period of 28 days and ignored that period in our calculations. However, a better selection of such period can autonomously reduce the length of the ignored period. We leave the process of measuring the number of warm-up days from simulation results to a future study. Furthermore, we assumed uniform control parameters for all zones within a building. However, there could be a case where non-uniform control parameters lead to higher energy efficiencies. For example, if a zone is located on the perimeter of a building where higher solar gain is possible, higher setpoints could be selected. The distribution of heat loads (e.g., lighting systems, appliances, heating/cooling systems, occupancy, etc.) could be studied under various factors (e.g., building size, construction category, climate, control parameters, etc.) introduced in this paper. The sensitivity of the energy usages based on the heat loads across different factors would 
provide more insight on how the primary sources of HVAC cooling and heating requirements may vary under different scenario which can potentially lead to more advanced control strategies.

The results presented in this paper suggests that in climates with relatively hot (e.g., Miami Florida (1A)) or cold (e.g., Fairbanks, Alaska (8)) temperatures throughout the year, selecting daily optimal setpoints instead of annual optimal setpoints would not lead to large improvements in the energy efficiency compared to the climates with high variations in temperatures, such as San Francisco, California (3C), Baltimore, Maryland (4A), Albuquerque, New Mexico (4B), Seattle, Washington (4C), Chicago, Illinois (5A), Denver, Colorado (5B), and Minneapolis, Minnesota (6A). In addition, as is illustrated in Figure 7 (a-c), there is a range of outdoor temperatures (e.g., $9-14{ }^{\circ} \mathrm{C}$ for small building and $8-11{ }^{\circ} \mathrm{C}$ for medium buildings), where the choice of setpoint would make a very small change in energy usage. Nevertheless, the daily optimal setpoint selection does make a large difference (up to 30\%) in energy usage at some outdoor temperatures. This evidence suggest that learning the relationship between optimal setpoints and outdoor temperatures, as well as associated energy savings can lead to more energy-efficient and comfort-driven HVAC operations. However, it is not often feasible to implement an exhaustive search in real buildings' HVAC controllers to learn optimal setpoints due to time related and comfort related constrains, as well as other constraints related to resources. Therefore, a future research direction is to study the techniques that learn optimal setpoints in actual buildings. These techniques should be able search the setpoint-outdoor temperature feature space to find optimal setpoints in a timely and efficient manner. Furthermore, setpoints can be selected on a finer scale (e.g., hourly) in HVAC control loop to improve the efficiency of the operations. However, there is again a trade-off between the complexity of the controller and the potential energy savings [36], which requires further investigations. Although the energy simulation models provided by the DOE were rigorously studied and tuned to represent the available building stock, each building might behave differently compared to the reference buildings in terms of the energy efficiency due to various simulation model parameters. In order to address this challenge, tuning the parameters can help reaching more realistic energy simulations results $[37,38]$.

In this study, we only focused on daily and annual optimal daily setpoints. However, by clustering optimal setpoints with respect to time, we can specify a few periods within a year, which could also be called "seasons" and then define seasonal optimal setpoints. This procedure would fill the gap between the annual and daily selection of optimal setpoints derivations. Learning the most energy efficient HVAC control parameters as a function of external variables (e.g., outdoor temperature) can be used as a technique to reduce the cost of HVAC system operations. Although occupants' thermal comfort requirements and building system constraints commonly play major roles in the selection of setpoints at the zone level, potential savings reported by this technique, with consideration of all requirements and constraints, can be used as a heuristic in trade-off analyses on implementing different energy retrofitting techniques for HVAC systems in commercial buildings. By doing so, stakeholders could make decisions based on more quantifiable costs and benefits.

\section{CONCLUSIONS}

In this paper, we introduced a systematic approach to study the effects of influential factors on building HVAC energy consumption, using building energy simulations. Specifically, we studied 6 factors (i.e., temperature setpoint, deadband, city (climate), construction category, size, occupancy schedule) and compared their impacts on the energy consumption using the DOE reference office building models. By using an N-way ANOVA, we first ranked these factors' influences on HVAC energy consumption, from largest to smallest, as follows: size, climate, occupancy schedule, construction category, deadband setpoints. We then derived a fixed setpoint that minimizes the energy consumption for the entire year (i.e., optimal annual setpoint) and calculated the associated energy saving for each climate and building size. Observing the fact that the variations in weather (e.g., outdoor temperature) also influence energy consumption on a daily basis, we continued to search daily optimal setpoints and their relationships with outdoor temperature and other building factors. We found that the optimal daily setpoints vary as outdoor 
temperature varies. We also studied optimal deadbands and demonstrated that deadbands have no correlation to weather conditions, as the larger the deadband, the higher the energy efficiency as it relaxes the performance of an HVAC system. Additionally, we found that outside a certain range of temperature (i.e., from -20 to $30^{\circ} \mathrm{C}$ ), choosing the highest setpoint for outdoor temperature above $30^{\circ} \mathrm{C}$ and lowest for outdoor temperatures below $-20^{\circ} \mathrm{C}$ would lead to minimal energy consumption, regardless of the climate, building size, or the construction category. While the outdoor temperature is within this range, the optimal setpoint depends on the building size. We also observed a range of outdoor temperatures (e.g., $9-14{ }^{\circ} \mathrm{C}$ for small buildings and $8-11{ }^{\circ} \mathrm{C}$ for medium buildings) where the setpoint selection would slightly influence the energy consumption. In addition, there are outdoor temperatures where the setpoint selection influence the energy consumption up to $30 \%$. The potential savings from selecting setpoints in the range of $22.5 \pm 3{ }^{\circ} \mathrm{C}$ in different climates and different sizes of buildings were also calculated. For small, medium and large office buildings, selecting daily optimal setpoints would lead to $10.09-37.03 \%$, $11.43-21.01 \%$, and $6.78-11.34 \%$ savings, respectively, depending on the climate. Daily optimal deadband selection of $0,1,2,4,5$, and $6 \mathrm{~K}$ would result in an average energy savings of -70.0, -34.9, 13.7, 9.6, 16.4, and $21.2 \%$, respectively, compared to baseline $3 \mathrm{~K}$. Daily optimal setpoint selection in ranges of $22.5 \pm 1{ }^{\circ} \mathrm{C}, 22.5 \pm 2{ }^{\circ} \mathrm{C}$, and $22.5 \pm 3{ }^{\circ} \mathrm{C}$ would result in an average savings $7.5,12.7$, and 16.4 $\%$, respectively. The findings presented in this paper can help building stakeholders to better understand approximate potential savings from energy aware selection of HVAC system control parameters, and therefore enable building stakeholders to decide on energy saving techniques. In addition, the annual and daily optimal setpoints derived for different sizes and climates can be used as guidelines or heuristics for building managers to select the HVAC control parameters.

\section{ACKNOWLEDGMENTS}

This material is based upon work supported by the National Science Foundation under Grant No. 1351701. Any opinions, findings, and conclusions or recommendations expressed in this material are those of the authors and do not necessarily reflect the views of the National Science Foundation.

\section{REFERENCES}

[1] Book BED. US Department of Energy, 20112010.

[2] U.S. Energy Information Administration. Emissions of Greenhouse Gases in the United States 2009, Distribution of total U.S. greenhouse gas emissions by end-use sector, Table 3. 2011;DOE/EIA0573(2009).

[3] Liu G, Liu B, Wang W, Fan Z, Athalye R, Moser D et al. Advanced Energy Retrofit Guide Office Buildings. 2011;20761.

[4] Siano P. Demand response and smart grids-A survey. Renewable and Sustainable Energy Reviews 2014;30:461-78.

[5] Mills E. Building commissioning: A golden opportunity for reducing energy costs and greenhouse-gas emissions. Lawrence Berkeley National Laboratory 2010.

[6] Xu X, Culligan PJ, Taylor JE. Energy saving alignment strategy: achieving energy efficiency in urban buildings by matching occupant temperature preferences with a building's indoor thermal environment. Appl Energy 2014;123:209-19.

[7] Ghahramani A, Jazizadeh F, Becerik-Gerber B. A knowledge based approach for selecting energyaware and comfort-driven HVAC temperature set points. Energy Build 2014;85:536-48.

[8] Nicol JF, Humphreys MA. Adaptive thermal comfort and sustainable thermal standards for buildings. Energy Build 2002;34:563-72. 
[9] Speijers J, Stanton JH, Naylor GR, Ramankutty P, Tester D. Skin comfort of base layer wool garments. Part 3: The effect of ethnicity on perceptions of comfort using Chinese and Australian wearers. Text Res J 2015;85:1167-80.

[10] Guan Y, Hosni M, Jones B, Gielda T. Literature review of the advances in thermal comfort modeling. Transactions-American Society of Heating Refrigerating and Air Conditioning Engineers 2003;109:908-16.

[11] Jendritzky G, de Dear R. Adaptation and thermal environment. In: Anonymous Biometeorology for adaptation to climate variability and change: Springer; 2009, p. 9-32.

[12] Ghahramani A, Tang C, Yang Z, Becerik-Gerber B. A Study of Time-Dependent Variations in Personal Thermal Comfort via a Dynamic Bayesian Network. In: Anonymous Sustainable HumanBuilding Ecosystems, p. 99-107.

[13] Ghahramani A, Tang C, Becerik-Gerber B. An online learning approach for quantifying personalized thermal comfort via adaptive stochastic modeling. Build Environ 2015;92:86-96.

[14] Deru M, Field K, Studer D, Benne K, Griffith B, Torcellini P et al. US Department of Energy commercial reference building models of the national building stock. 2011.

[15] Freire RZ, Oliveira GH, Mendes N. Predictive controllers for thermal comfort optimization and energy savings. Energy Build 2008;40:1353-65.

[16] Haines RW, Myers M. HVAC Systems Design Handbook, Fifth Edition . : McGraw-Hill Education, 2009.

[17] Standard A. Standard 62.1-2010 (2010). Ventilation for Acceptable Indoor Air Quality, Atlanta, GA. American Society of Heating, Refrigerating and Air-Conditioning Engineers, Inc.

[18] Hoyt T, Lee KH, Zhang H, Arens E, Webster T. Energy savings from extended air temperature setpoints and reductions in room air mixing. 2009.

[19] Hoyt T, Arens E, Zhang H. Extending air temperature setpoints: Simulated energy savings and design considerations for new and retrofit buildings. Build Environ 2014.

[20] Fernandez N, Katipamula S, Wang W, Huang Y, Liu G. Energy Savings Modeling of Standard Commercial Building Re-tuning Measures: Large Office Buildings. : Pacific Northwest National Laboratory, 2012.

[21] Kazanci OB, Olesen BW. The Effects of Set-Points and Dead-Bands of the HVAC System on the Energy Consumption and Occupant Thermal Comfort. 2013.

[22] Lakeridou M, Ucci M, Marmot A, Ridley I. The potential of increasing cooling set-points in airconditioned offices in the UK. Appl Energy 2012;94:338-48.

[23] Huang Y, Niu J, Chung T. Study on performance of energy-efficient retrofitting measures on commercial building external walls in cooling-dominant cities. Appl Energy 2013;103:97-108.

[24] Lin H, Hong T. On variations of space-heating energy use in office buildings. Appl Energy 2013;111:515-28.

[25] Taleghani M, Tenpierik M, van den Dobbelsteen A, de Dear R. Energy use impact of and thermal comfort in different urban block types in the Netherlands. Energy Build 2013;67:166-75.

[26] Taleghani M, Tenpierik M, van den Dobbelsteen A. Indoor thermal comfort in urban courtyard block dwellings in the Netherlands. Build Environ 2014;82:566-79.

[27] Garg V, Chandrasen K, Tetali S, Mathur J. EnergyPlus simulation speedup using data parallelization concept. 2010:1041-7. 
[28] Mechri HE, Capozzoli A, Corrado V. Use of the ANOVA approach for sensitive building energy design. Appl Energy 2010;87:3073-83.

[29] Ghahramani A, Dutta K, Yang Z, Ozcelik G, Becerik-Gerber B. QUANTIFYING THE INFLUENCE OF TEMPERATURE SETPOINTS, BUILDING AND SYSTEM FEATURES ON ENERGY CONSUMPTION. 2015.

[30] Briggs RS, Lucas RG, Taylor ZT. 4611 Climate Classification for Building Energy Codes and Standards: Part 2--Zone Definitions, Maps, and Comparisons. ASHRAE Transactions-American Society of Heating Refrigerating Airconditioning Engin 2003;109:122-30.

[31] Energy Information Administration. 2012 Commercial Buildings Energy Consumption Survey (CBECS), Summary Tables, Tables B1. Summary table: total and means of floorspace, number of workers, and hours of operation. 2015.

[32] Michaels J, Leckey T. Commercial buildings energy consumption survey. URL http://www.eia.doe.gov/emeu/cbecs 2003.

[33] Khosrowpour A, Gulbinas R, Taylor JE. An Empirical Comparison of Internal and External Load Profile Codebook Coverage of Building Occupant Energy-Use Behavior.

[34] Yang Z, Becerik-Gerber B. A model calibration framework for simultaneous multi-level building energy simulation. Appl Energy 2015;149:415-31.

[35] Yang Z, Becerik-Gerber B. Coupling occupancy information with HVAC energy simulation: a systematic review of simulation programs. 2014:3212-23.

[36] Gruber M, Trüschel A, Dalenbäck J. Energy efficient climate control in office buildings without giving up implementability. Appl Energy 2015;154:934-43.

[37] Menezes AC, Cripps A, Bouchlaghem D, Buswell R. Predicted vs. actual energy performance of non-domestic buildings: Using post-occupancy evaluation data to reduce the performance gap. Appl Energy 2012;97:355-64.

[38] Olofsson T, Mahlia T. Modeling and simulation of the energy use in an occupied residential building in cold climate. Appl Energy 2012;91:432-8. 